\title{
Rural Drinking Water Supply in Karnataka - A Case Study of Mysore Thaluk
}

\author{
${ }^{1}$ Sandeep Raj.K and ${ }^{2}$ Dr.V.Shanmugam \\ ${ }^{1}$ (Research Scholar, DOS in Economics \& Co-operation, Manasagangothri, Mysore, Karnataka State, India.) \\ ${ }^{2}$ (Associate Professor of Economics, Maharaja's College, University of Mysore, Mysore Karnataka State, India)
}

Abstract: Now a day the drinking water shortage is arising due to many reasons like pollution, chemicals etc., and also World Bank assists some of the programmes relating to the drinking water supply in some countries. Here, in India we have the local government namely, Panchayat Raj Institutions to meet the needs of the local people in rural area and municipalities in urban areas. Even if there are number of programmes, schemes relating to the drinking water supply to people, they are not effectively implemented by local bodies. This paper studies the rural drinking water supply in Mysore Thaluk belongs to Mysore District in Karnataka State and it try to enlighten the work efficiency of local bodies with concern to the drinking water supply the study region.

\section{Introduction}

Clean normal water is a standard necessity of life. India with $2.4 \%$ of the world's full place has $16 \%$ of the people; but has just $4 \%$ of the total available fresh water. This clearly suggests the need for water assets development, conservation and their optimum use. $90 \%$ of our planet is occupied by water as oceans and seas. Only $0.5 \%$ can be obtained consumption. Actually this meager quantity is unequally distributed. Every year about 5, 66,000 cubic meter of water disappears from the earth's surface. $80 \%$ of it over the sea the exact same level of water falls to the planet earth, but just 1, 10,000 cubic kilo meter within the landmasses, that 71,000 cubic kilo meter disappears directly. This leaves the typical bulk of water working off the landmasses every year as about 39,000 cubic kilo meters that $64 \%$ moves off very quickly.

Drinking tap water or potable water is safe enough to be eaten by individuals or used in combination with the lower risk of immediate or long-term harm. In many produced countries the water equipped to households, commerce and industries matches drinking common although just a very small percentage is clearly eaten in food preparation.

Water has always been a significant and living sustaining drink to individual and essential to the survival of all organisms excluding fat. Water composes around $70 \%$ of the body by mass. Water offer may be the provision of water by the general public utilities, industrial business neighborhood Endeavour or by persons usually system of sends and pipes, irrigation is included separately.

In 2010 about $85 \%$ of the world wide citizenry had usage of piped water offer through houses connections or even to a water resource through other indicates than houses including stand pipes "water kiosks" secured rises and secured wells. Nevertheless, about $14 \%$ did not have usage of an improved water resource and had to utilize unprotected wells or rises, canals, lakes or rivers for their water needs.

\section{Water Quality}

Variations in water quality may significant domestically, but are difficult to blend in a important way at national level. Additionally water quality must certainly be indicated not merely in expression of physical, organic \& chemical variables but in addition in accordance with quality involve the employment, which means evaluation of water quality involve the utilization of water quality grid, defining quality classes according to several standards and variables. With increasing pressure on normal new water in elements of the entire world, other resources of water are growing in importance. These non-conventional resources of water signify complementary source resources that may be considerable in regions suffering from severe scarcity of renewable water resources.

\section{Importance Of Water Supply}

Water baby the most frequent substance on the earth. It covers more than $70 \%$ of the earth's surface. It floods oceans, water, and waters and is in the ground and in the air we breathe. Water is everywhere regardless of language or tradition, all human gives that basic requires that's required for survival. We consume water, tool with it and shower it, sprinkle our lawns with it, fill our back yard swimming pools with it and actually build Design Park based on it. 
We but, get its abundance for given when a lot of the world especially sub-Saharan Africa, including Zambia, entry to wash water is really a luxury. Over fifty percent of Africa's village's pond entry to wash water supply. In most of the villages, women and young ones must go up ten miles each and every day holding heavy buckets to fetch the day's water method of getting potable water due to their households.

Without water, there might be number life. In fact everything consists largely of water. Our human body is all about two-third water and chicken is all about three-fourth water and a blueberry is all about fourfifth water. Many scientists think so it started in water, in salty water of the sea. Water helps to keep the earth's climate from finding warm or also cold. Land absorbs and produces temperature from the child quickly. But oceans absorb and launch the sun temperature slowly. Therefore breezes from the oceans bring temperature to the land in winter and coolness in summer.

Throughout the record, water has been people's servant and their master. Great society has arisen where water materials were plentiful. They've dropped when these materials failed. People have killed one another for muddy water whole.

\section{Background Of The Study}

Rural water source is one of many major issues that's been resolved by the government and efforts created towards tackling the disaster in providing safe and adequate water to the rural people, currently the problem has become particularly significant in rural areas. A review of the government's attempts in applying various programmes, guidelines, followed shows limited development in providing ample level of portable water to any or all people. Several factors like increases urbanization ultimately causing negligence of traditional water sources, not enough water administration, resource depletion as a result of over exploitation of existing resources, limited institutional setup in addressing the problem have led to the intensity of the problem within the years.

Various proportions of the issues have already been resolved for the efficient implementation of rural water source schemes. This is dependent on several factors social, specialized, economic legitimate, and political. It is very important to understand the existing condition \& the complexities in order to address the problem in the situation of task design \& implementation, factors affecting sustainability of rural water source programmes.

In the new years we are able to also start to see the source and need connection as a result of economic growth followed by population increases, over exploitation and skip administration of organic resources and urbanization are resulting in decreasing method of getting clean water and other environment goods. Several issues are being seriously resolved such as for instance water administration areas decentralization in water allocation, suitable utilization of water, water pricing, specialized solution and awareness generation, conserving water and utilizing it judiciously has come about just with raising lack and limbs in weather problems causing disparity in water availability.

\section{Rural Water Supply In Karnataka}

Usage of normal water and satisfactory sterilization are immediate pre requisites for recognizing improved human health and welfare. As per 20013.84 crore persons reside in rural areas of their state spread around 59,203 habitations. Each one of these habitations are provided with water supply. Out of 59,203 habitations in Karnataka 32,236 habitation are fully covered and 26,967 are partially covered as by the end of the march 2010.

The normal water systems of their state include give sends, bore wells, piped water supply systems and small water supply systems, the main water supply for normal water wants is floor water in the state. Because of around exploitation of floor water for sources was taken by their state about 1,162 leaves and trenches 2,150 check dams 806 percolation tanks. All through 2011-12 action strategy their state created available $20 \%$ of key government give because of this program and the projected level of systems was 325.65 crore.

World Bank helped Jal Nirman Tasks is really a demand sensitive challenge applied in 11districts of upper Karnataka. Under that challenge water supply challenge has been adopted in 744 Gram Panchayats having 3061 villages and streets strain systems were adopted in 1523 villages at a projected price of Rs 997 Crore.

\section{Objectives Of The Study}

1. To examine the government policies and programmes regarding rural drinking water supply.

2. To examine the problems related to rural drinking water supply in Mysore Thaluk. 


\section{Methodology}

This is the case study of rural water drinking supply in Mysore Thaluk. The study is based on the primary and secondary data. The primary data is collected through a questionnaire so the respondents are in Yelwala and Hinkal village in Mysore Thaluk, Mysore District.

Secondary data is collected from books, journals, published articles and reports, magazines and also most from the internet sources, www.google.com, www.yahoo.com, economic survey of India and economic survey of Karnataka 2013-14 etc.,

As the questionnaire itself administered one the survey is kept simple and user friendly, words used in questionnaire are readily understandable to all respondents, also technical jargons are avoided to ensure that, there is no confusion for respondents. Data was processed and interpreted using simple statistical tools.

VIII. Rural Drinking Water Supply In Karnataka.

Table No.1-Rural Water Scenario in Karnataka

\begin{tabular}{|c|c|c|}
\hline Service levels of water (lpcd) & Habitations (No.) & Percentage \\
\hline $55 \&$ above & 5581 & 9.35 \\
\hline Less than55 & 50365 & 85.29 \\
\hline Quality Affected & 3207 & 5.36 \\
\hline Total & 59753 & 100 \\
\hline
\end{tabular}

Source: Economic Survey of Karnataka 2013-14.

Foot Note: Norms for Rural Area $=551 \mathrm{pcd}$.

The above table reveals the rural water scenario in Karnataka and on the whole 59753 habitations in the state are covered with different norms like 55lpcd and above, less than 55lpcd and quality affected norms. Here 55 and above lpcd is covered of $9.35 \%$ and less than $551 \mathrm{pcd}$ is of $85.29 \%$ and quality affected of $5.36 \%$.

Table No. 2-Distribution of households by source of drinking water in Karnataka

\begin{tabular}{|c|c|c|c|c|c|c|}
\hline Source of water & Total & Percent & Rural & Percent & Urban & Percent \\
\hline $\begin{array}{c}\text { Tap water } \\
\text { treated }\end{array}$ & 5432724 & 41 & 1797502 & 23 & 6025 & 58 \\
\hline $\begin{array}{c}\text { Tap water } \\
\text { untreated }\end{array}$ & 3274240 & 25 & 2634613 & 34 & 1750 & 17 \\
\hline Covered well & 131305 & 1 & 79637 & 1 & 876 & 9 \\
\hline Uncovered well & 1051685 & 8 & 855626 & 11 & 1269 & 12 \\
\hline Hand pump & 729630 & 6 & 662370 & 8 & 11 & 112 \\
\hline Tube well & 2101712 & 16 & 1539109 & 20 & 1 \\
\hline Other sources & 458615 & 3 & 295339 & 4 & 31 & 0.3 \\
\hline All sources & 13179911 & 100 & 7864196 & 100 & 58 & 0.6 \\
\hline
\end{tabular}

Source: Economic Survey of Karnataka 2013-14.

The above table shows the distribution of households by source of drinking water in Karnataka and it reveals more households $58 \%$, in the urban are connected with tap water (treated) comparing to rural area as it shows $23 \%$. Comparing to urban households who are getting untreated water is very less as $17 \%$, as the data shows in rural area $34 \%$.

Table No.3- Water Supply Coverage under Bharat Nirman. NRDWP Programme

\begin{tabular}{|c|c|c|c|c|c|c|c|}
\hline \multirow{2}{*}{ Year } & \multirow{2}{*}{$\begin{array}{c}\text { Total } \\
\text { Coverage }\end{array}$} & \multicolumn{7}{|c|}{ Coverage of Habitations (Nos.) } \\
\cline { 3 - 8 } & & $\mathbf{0 - 2 5 \%}$ & $\mathbf{2 5 \% - 5 0 \%}$ & $\mathbf{5 0 \% - 7 5 \%}$ & $\mathbf{7 5 \% - 1 0 0 \%}$ & Above 100\% & $\begin{array}{c}\text { Quality } \\
\text { Affected }\end{array}$ \\
\hline $2008-09$ & 1078 & - & - & - & - & - & - \\
\hline $2009-10$ & 7668 & - & - & - & - & - & - \\
\hline $2010-11$ & 6130 & 1200 & 1146 & 952 & 1204 & 2708 & 1495 \\
\hline $2011-12$ & 8757 & 885 & 2237 & 761 & 596 & 2783 & 2023 \\
\hline $2012-13$ & 13284 & 1338 & 4197 & 1213 & 637 & 3876 & 347 \\
\hline $\begin{array}{l}2013-14 \\
\text { uptoct.13 }\end{array}$ & 3015 & 331 & 743 & 947 & 446 & 201 & \\
\hline
\end{tabular}

Source: Economic Survey of Karnataka 2013-14.

Table No.4-Sources of Drinking Water in Mysore Thaluk, Mysore District.

\begin{tabular}{|c|c|}
\hline Sources & Mysore Thaluk \\
\hline Well & $0 \%$ \\
\hline Borewell & $24 \%$ \\
\hline Tank & $0 \%$ \\
\hline Piped Water & $76 \%$ \\
\hline Total & $\mathbf{1 0 0} \%$ \\
\hline
\end{tabular}


The above data was collected is based on primary data which was collected through questionnaire and it reveals that more than half of the households are getting drinking water through the source of piped water i.e., $76 \%$ and $24 \%$ of the households are getting from the Borewell source.

\section{Findings And Conclusion}

The Rural Drinking Water-A Case Study of Mysore Thaluk revealed the following findings...

$>$ Total households using tapped water (treated) in Karnataka is only $41 \%$ and tapped water (untreated) is about $25 \%$.

$>$ The study reveals that only $1 \%$ of the well is covered and $8 \%$ of the uncovered in Karnataka.

$>23 \%$ of the households in rural area in Karnataka are getting tapped treated water, while comparing to urban area in the state is more as $58 \%$.

$>17 \%$ of the households are getting drinking water through tapped untreated water in urban area and $34 \%$ of the households in rural.

> Programmes related to drinking water supply are not effectively implemented in Karnataka as well as in the study region.

$>$ Panchayat Raj Institutions are directly responsible for the failure of supplying of drinking water in rural areas in Karnataka as well as in the study region.

\section{References}

[1]. Diwakar H and N Nagaraj (2002), Impact of Water Pollutin on Food Security and Environment: Bearing the Brunt, Waste land News, August-October.

[2]. Government of Karnataka (2002-03), Annual Report, Rural Development and Panchayat Raj Department, Banglore.

[3]. Government of Karnataka (2000), Rural Water Supply and Sanitation in Karnataka- Strategy Paper 2000-2005, Rural Development and Panchayat Raj Department, Banglore.

[4]. Karnatka Economic Survey Report 2013-14.

[5]. Mysore at a Glance 2012-13. 